\title{
Solidarity and autonomy: two conflicting values in English and French health care and bioethics debates?
}

\author{
Marie Gaille ${ }^{1}$ Ruth Horn ${ }^{2}$
}

Published online: 5 December 2016

(C) Springer Science+Business Media Dordrecht 2016

Although bioethics has had an international and universal outlook since its origin, divergent views on ethical questions in health care practice continue to exist across countries, even within the small continent of Europe [1-5]. In the literature, the liberal approach of Anglo-American bioethics is often seen as opposed to the solidarity-based approach of continental European bioethics [6-8]. Yet, despite the importance of recognising these different value systems, we believe that the opposition between Anglo-American and European bioethics does not capture the complexity of the situation. Bioethics and health care debates that take place in various countries influence each other and affect the way normative concepts are interpreted and used in different national contexts. If an international approach to bioethics is to be furthered and dialogue between countries improved, the meaning and use of dominant normative concepts in different countries needs to be better explored.

To that end, we organised a two-day workshop entitled, 'Solidarity and Autonomy-Two conflicting values in bioethics? English and French perspectives on two core values in health care and medicine'. Funded by the Wellcome Trust (106152/Z/14/7), this workshop brought together philosophers and political and social scientists from England and France, and it took place on 16th-17th February 2015, at Linacre College, Oxford. The articles in this special issue have grown out of the proceedings of that workshop.

Ruth Horn

ruth.horn@ethox.ox.ac.uk

Marie Gaille

marie.gaille@univ-paris-diderot.fr

1 Laboratoire SPHERE (UMR 7219), CNRS, University of Paris Diderot, bâtiment Condorcet, case 7093, 5 rue Thomas Mann, 75205 Paris Cedex 13, France

2 The Ethox Centre, Nuffield Department of Population Health, University of Oxford, Old Road Campus, Oxford OX3 7LF, UK 
England and France are two countries with seemingly divergent ethical approaches to medical practices [3, 9-11]. Whereas the liberal English tradition is commonly seen as promoting respect for patient autonomy as its dominant principle, the French perspective is seen as promoting the physician's sense of responsibility for and solidarity with the vulnerable patient [12-15]. Scholars and professionals in both countries sometimes take a critical stance towards the other country's dominant values. In England, solidarity is discussed as an unduly vague concept (see, e.g., [3, 16-18]), whereas critical voices in the French debate question the concept of autonomy [19, 20]. Despite such conflicts, we believe that both autonomy and solidarity are core values in bioethics.

Our workshop showed how the exchange of ideas in the international bioethics debates and in medical practice influences the understanding of ideas, values, and concepts in one country, and how each country translates them in their own way. The various presentations further highlighted how the circulation of ideas generates complex value patterns, accommodating both autonomy and solidarity. The papers presented also confirmed the topicality of the concepts of autonomy and solidarity, as well as of the closely related concepts of justice and privacy often used in the American context. The papers highlighted the use, as well as the limitations, of these concepts for normative reflection on health care policies and practices in England and France, but also in the US, a country that has influenced the European bioethical debate from its beginning.

In order to address the complexity of the relationship between autonomy and solidarity and their meanings, we invited scholars from bioethics, philosophy, political science, anthropology, and sociology to reflect on the various aspects of this relationship. The articles published in this special issue offer an examination on different levels: (1) analysis of concepts and theories; (2) inquiry about the uses of terms and their translations; (3) study of legal system and institutional changes; (4) history of moral and political ideas; (5) exploration of practices; (6) and analysis of public debates. This multidisciplinary approach results in a critical and descriptive assessment of the countries studied and generates recommendations and suggestions on how to integrate both autonomy and solidarity into health care systems.

In the first article of this issue, 'When Marcel Mauss's Essai sur le Don Becomes The Gift: Variations on the Theme of Solidarity' [21], French sociologist Simone Bateman examines the English translation of Mauss's 1923 essay. According to Bateman, this essay is one of the basic primary sources for the contemporary debate about solidarity and autonomy. As she shows, today, primary sources are often used in an indirect way (through the 'lenses' of the commentaries made about them) and without taking into account the effects of the translation of the original notions and terms. However, translation plays a key role in the international exchange of ideas and debates about them. Hence, Bateman argues, it is essential to be aware of how words and frames of thought 'travel' both in time and space, and to clarify the theoretical and normative impact of this travel. With that in mind, she examines what was 'lost in translation' and also gained in the Anglo-American social sciences when Mauss's Essai sur le Don was translated into English as The Gift in 1954. She argues that this translation implies the disappearance of Mauss's concern for what underlies acts of giving, receiving, and 'repaying' or 'returning': the desire to 
sustain a network of relationships and the collective benefits that derive from its continued existence. In return, she also stresses what is gained: a paradigm for analysing the use of human body parts and substances for medical and research purposes. Bateman analyses this issue on the basis of an examination of works by political scientist Richard Titmuss in the UK and sociologist Renée C. Fox and historian Judith Swazey in the US. They all used Mauss's idea of the gift (don) to highlight the fundamental structure of the biomedical practices they were studying, respectively, blood donation and organ transplantation. Finally, Bateman puts forward the hypothesis that a new translation of the don as an 'act of giving' could allow for a broader understanding of giving, with unquestionable links to the Durkheimian concept of solidarity, and more generally, to the Durkheimian school of sociology in which Mauss was trained.

French anthropologist Sylvie Fainzang shares Bateman's interest in the semantic change of ideas and concepts in different contexts. In her article, 'From Solidarity to Autonomy: Towards a Redefinition of the Parameters of the Notion of Autonomy' [22], Fainzang argues that autonomy and solidarity can coexist if autonomy is not understood from an individualistic perspective. She draws on her long-standing research on the patient-physician relationship and the role of the family in individuals' health attitudes (e.g., ethnographic studies of associations of former drinkers, self-medication, and medical secrecy in France). Fainzang highlights the differences between patients with a Catholic or Protestant background with respect to self-medication and clinical encounters. According to her observations, families of patients with a Catholic background are more involved in treatment decisions than families of patients with a Protestant background. Exploring the role of the family in different contexts, she shows that the concept of 'family patient support' can be an expression of solidarity, where families and professionals share their responsibilities regarding care of the patient. Fainzang shows that even if autonomy is encouraged in 'family patient support', solidarity remains at the root of the practice. Although she argues that the focus on the role of the family can endanger individual autonomy, she shows that autonomy is not at risk in all cases. She concludes that depending on the context and the social use, the notion of autonomy can go beyond its individualistic meaning and extend to a collective subject. In her article, Fainzang emphasises that the principle of solidarity can underpin the implementation of the principle of autonomy in order to protect the patient.

Similarly, in the third article of the special issue, we (Marie Gaille and Ruth Horn) observe the increasing importance of the value of autonomy in the context of the end-of-life debate in France. We show that autonomy has for a long time been considered a foreign Anglo-American idea that needs to be associated with solidarity before it can be accepted as an important element in medical practice and law. In our article, "The Role of "Accompagnement" in the End-of-Life Debate in France: From Solidarity to Autonomy' [23], we explore the different stages in the development of this debate over the past twenty-five years. Initially, solidarity was (and still is) a key value of the French health care system. The notion of autonomy did not have any place in the debate. More recently, however, the notion of autonomy has imposed itself in the end-of-life debate, following the rise of the patient rights movement. This development, we argue, was made possible through 
the association of autonomy and solidarity. Autonomy has become a value whose importance is no longer disputed. More precisely, we show how the use of the French notion of 'accompagnement' (support) captures this shift in the end-of-life debate. Initially, this notion was promoted by the French palliative care movement to describe 'good' end-of-life care, but nowadays, it is employed in a different context. The notion of 'accompagnement' is increasingly used in order to reconcile the emerging demand to respect patient autonomy with the social responsibility to protect the vulnerable, i.e., the dying person. We conclude that in such a context, autonomy refers to a relational rather than an atomistic conception of the individual.

The French context as described here is representative of what Barbara Prainsack and Alena Buyx term the continental European approach to solidarity and autonomy. In their article, 'Thinking Ethical and Regulatory Frameworks in Medicine from the Perspective of Solidarity on Both Sides of the Atlantic' [24], they describe this approach as opposed to that of the Anglo-Saxon world, which is based on the notion of the autonomous individual. The latter underpins Western conceptualisations of rights and freedoms, where the individual is the central bearer of rights and duties. The idea that individual autonomy is a core characteristic of human beings is also the basis of many moral, ethical, political, and economic frameworks in the domain of medicine. One of the results of this approach is the assumption that we can make a clear distinction between self-interest and care for others. Contrary to this view, Prainsack and Buyx argue that solidarity has much to offer in addressing challenges in the field of medical research and practice, on both sides of the Atlantic. In order to support this claim, the authors provide a brief overview of the history of scholarship on solidarity in Europe and North America. Based on their historical analysis, they elaborate a working definition of solidarity that highlights its utility for guiding policy and practice. Taking the case of the governance of data use as an example, Prainsack and Buyx highlight how a solidarity-based perspective could be fruitfully employed on both sides of the Atlantic in order to help modify existing practices.

Expanding on the differences between continental European and AngloAmerican approaches, Jennifer Merchant seeks to compare what contemporary French and US societies understand to be the principle of autonomy or the 'right to privacy' with what actually happens to real people in real lives through enacted public policy in health care. In her article, 'Privacy, Autonomy, and Public Policy: French and North American Perspectives' [25], the author provides an overview of French and American law and politics and shows how the concepts of autonomy and privacy figure in them. She briefly touches on the normative foundations of each country's approach and examines how these different approaches are reflected in health care law and practices in France and the US. As Merchant emphasises, the concept of privacy is a core value in North-American discourse relative to individual rights, whereas the human rights principle and respect of bodily integrity and human dignity prevail in France. However, analysing contemporary events and recent developments, she shows that overlaps do exist. Merchant argues that the effects of globalisation made each country feel the need to be more receptive to new principles (the right to privacy in France; human and social rights in the US) in order to renew regulatory frameworks for contemporary challenges. 
Similarly, in the final article of this issue, 'Solidarity, Justice, and Recognition of the Other' [26], Ruud ter Meulen argues that the liberal rights-based views that have dominated bioethics for many years are being increasingly challenged, and there have been growing calls for a renewed approach to bioethics. In view of these new challenges, the author asserts the importance of integrating the concept of solidarity into bioethics. However, in order for solidarity to play a role in bioethics, he argues that a philosophical understanding of the concept needs to be developed and offers a philosophical reflection on the concept of solidarity. Tracing the origins of solidarity, as the core value underpinning European health and welfare systems, he questions whether the feeling of mutual responsibility still applies to contemporary societies. The introduction of market reform, personal choice, and individual private financial responsibility, seem to make solidarity a redundant concept that, due to its alleged communitarian content, is difficult to reconcile with the emphasis on individual freedom and autonomy in the delivery of health care. Instead, there is increased attention to the concept of justice, which is based on liberal and individualistic approaches to the allocation of resources and access to health care. Ter Meulen suggests, however, that the principle of justice sets limits to individual satisfactions and needs because it prioritises what is right over what is good. In spite of the growing influence of liberal justice, a renewed attention to the concept of solidarity in theoretical bioethics is seen as a corrective to the shortcomings of justice. The author concludes that solidarity is not an alternative to a rights-based concept of justice, but must be considered as a necessary complement to it.

We believe that the findings of this workshop make a significant contribution to the international approach to bioethics and further the international dialogue in this field. By taking into account both socio-cultural and conceptual aspects, the articles included here show how seemingly contradictory values, such as autonomy and solidarity, are sometimes much closer to each other than it is assumed. Rather than being opposed, these values actually complement each other. The acknowledgment of 'other' ethical stances and cultures is an important step towards broadening the bioethical debate. Such a step was far from obvious in the early 1980s, as was highlighted by Fox and Swazey [2], and again by H. Tristram Engelhardt in the early 2000s [4]. With this special issue, we want to propose two further stages that we consider to be important to the recognition of cultural plurality: firstly, consider how various ethical positions communicate with and infuse one another, thanks to the circulation of terms and ideas; and secondly, comprehend the implications of this reciprocal influence and its potential to generate new and innovative ethical perspectives. Such new perspectives may not solve every disagreement and ethical conflict, but we believe that moving beyond a discourse that presents ethical principles in opposition will allow us to better grasp the complexity of ethical life. Waiving the strict opposition between autonomy and solidarity allows us to better address contemporary challenges in health care and propose new ways to deal with them. 


\section{References}

1. Fox, R.C., and J.P. Swazey. 1984. Medical morality is not bioethics-Medical ethics in China and the United States. Perspectives in Biology and Medicine 27 (3): 336-360.

2. Fox, R.C., and J.P. Swazey. 2008. Observing bioethics. New York: Oxford University Press.

3. Dickenson, D. 1999. Cross-cultural issues in European bioethics. Bioethics 13: 249-255.

4. Engelhardt Jr., H.T. 2001. The many faces of autonomy. Health Care Analysis 9: 293-297.

5. Hayry, M. 2003. Are there distinctly European values in bioethics, and if there are, what are they? Theoretical Medicine and Bioethics 24 (3): 199-214.

6. Rendtorff, D.D., and P. Kemp. 2000. Basic ethical principles in european bioethics and biolaw. Vol. I: Autonomy, dignity, integrity and vulnerability. Barcelona: Center of Ethics and Law, Institut Borja de bioètica.

7. ten Have, H., and B. Gordijn (eds.). 2001. Bioethics in a European perspective. Dordrecht: Kluwer.

8. Schotsmans, P. 2015. Present and future: A personal and narrative perspective from the European continent. In The voices and rooms of European bioethics, ed. R. Huxtable, and R. ter Meulen. London: Routledge.

9. Horn, R. 2011. Euthanasia and end-of-life practices in France and Germany: A comparative study. Medicine, Healthcare and Philosophy 16 (2): 197-209.

10. Horn, R. 2012. Advance directives in England and France: Different concepts, different values, different societies. Health Care Analysis 22 (1): 59-72.

11. Horn, R., and A. Kerasidou. 2016. The concept of 'dignity' and its use in end-of-life debates in England and France. Cambridge Quarterly of Healthcare Ethics 25 (3): 404-413.

12. Gaille, M. 2010. La valeur de la vie. Paris: Les Belles Lettres.

13. Gaille, M. 2011. Le désir d'enfant-histoire intime et enjeu politique. Paris: Presses Universitaires de France.

14. Gaille, M. 2014. Cabanis, anthropologie médicale et pensée politique. Paris: Editions du CNRS.

15. Horn, R. 2014. 'I don't need my patients' opinion to withdraw treatment': Patient preferences at the end-of-life and physician attitudes towards advance directives in England and France. Medicine, Health Care and Philosophy 17: 425-435.

16. Prainsack, B., and A. Buyx. 2011. Solidarity: Reflections on an emerging concept in bioethics. Nuffield Council on Bioethics. http://www.nuffieldbioethics.org/solidarity-0. Accessed November $11,2016$.

17. Prainsack, B., and A. Buyx. 2012. Solidarity in contemporary bioethics. Bioethics 26: 343-350.

18. Dickenson, D. 2013. Me medicine vs. we medicine. New York: Columbia University Press.

19. Pelluchon, C. 2008. L'autonomie brisée: bioéthique et philosophie. Paris: Presses Universitaires de France.

20. Fassin, D. 1998. Les figures urbaines de la santé publique. Paris: La Découverte.

21. Bateman, S. 2016. When Marcel Mauss's Essai sur le Don becomes The Gift: Variations on the theme of solidarity. Theoretical Medicine and Bioethics. doi:10.1007/s11017-016-9384-6.

22. Fainzang, S. 2016. From solidarity to autonomy: Towards a redefinition of the parameters of the notion of autonomy. Theoretical Medicine and Bioethics. doi:10.1007/s11017-016-9385-5.

23. Gaille, M., and R. Horn. 2016. The role of 'accompagnement' in the end-of-life debate in France: From solidarity to autonomy. Theoretical Medicine and Bioethics. doi:10.1007/s11017-016-9389-1.

24. Prainsack, B., and A. Buyx. 2016. Thinking ethical and regulatory frameworks in medicine from the perspective of solidarity on both sides of the Atlantic. Theoretical Medicine and Bioethics. doi:10. 1007/s11017-016-9390-8.

25. Merchant, J. 2016. Privacy, autonomy, and public policy: French and North American perspectives. Theoretical Medicine and Bioethics. doi:10.1007/s11017-016-9388-2.

26. ter Meulen, R. 2016. Solidarity, justice, and recognition of the other. Theoretical Medicine and Bioethics. doi:10.1007/s11017-016-9387-3. 